\title{
DISCURSO DEL PRESIDENTE DEL COLEGIO DE ABOGADOS
}

\section{Sr. Manuel Cortés Barrientos en el lanzamiento de la}

Revista de Derecho

El Colegio de Abogados de la Cuarta Región de Coquimbo, ve con agrado y mira con esperanza la Revista que la Escuela de Derecho de la Universidad Católica del Norte, entrega hoy al conocimiento público.

Es por vez primera, que este hecho docente, académico y de extensión ocurre en nuestra jurisdicción.

Es motivo entonces de contentamiento saber que comienza a plasmarse en nuestra realidad regional el espíritu universitario que busca en la investigación jurídica, proyectar un pensamiento que es nuestro.

Así como no puede haber un carpintero sin banco, ni un relojero sin lente, ni un militar sin uniforme, tampoco creemos, puede haber abogados sin libros y revistas jurídicas.

Cuando creemos que el Abogado es tal, en función del estudio, la lectura es sustento diario del intelecto, para discurrir en los conocimientos ya sabidos pero que siempre habrá que remozar, así como sacudimos el polvo en los anaqueles en que los libros reposan

Pero también la lectura servirá para iluminarnos y apreciar el pensamiento ajeno, que en materias jurídicas es una manera de aprehender la vida y comprender el universo.

Esa es la tarea que comienza a cumplir con la revista de hoy, la Escuela de Derecho de la Universidad Católica del Norte.

Es la obra primera que saludamos con alborozo.

Es un resultado concreto de un esfuerzo intelectual de los Académicos de esa Universidad, encabezados por la Sra. Directora Luz María Reyes Santelices, sin cuya dinámica iniciativa y ejecutor paso, esta revista no se habría concretado.

Saludamos esa Casa de Estudios Superiores cuya Escuela de Derecho, hoy abre perspectivas distintas al trabajo de creación profesional de los estudiantes, pero que también ha de servir a los abogados de la Región de Coquimbo. 
Creemos que la instancia universitaria puede ser el lugar de encuentro para la extensión que en forma paralela ejecutan la Asociación de Magistrados, el Círculo de Mujeres Abogados y el propio Colegio de Abogados de la Cuarta Región de Coquimbo.

Entonces recibamos con contentamiento este primer número de la Revista de la Escuela de Derecho, y dejemos constancia de la vocación de los Abogados para que, aunando esfuerzos, hagamos de nuestro territorio jurisdiccional, el campo fértil para mejores proyecciones de desarrollo académico, profesional y personal. 